\title{
Chemical and enzymatic synthesis of the alginate sugar nucleotide building block: GDP-D-mannuronic acid
}

\author{
Laura Beswick, Sanaz Ahmadipour,^Jonathan P. Dolan, ${ }^{\$}$ Martin Rejzek, ${ }^{\wedge}$ \\ Robert A. Field^ and Gavin J. Miller*
}

Lennard-Jones Laboratory, School of Chemical and Physical Sciences, Keele University, Keele, Staffordshire, ST5 5BG, U.K.

*Corresponding author. Email: g.j.miller@keele.ac.uk

$\$$ Current address: School of Chemistry and Astbury Centre for Structural Molecular

Biology, University of Leeds, LS2 9JT, UK

${ }^{\wedge}$ Department of Biological Chemistry, John Innes Centre, Norwich Research Park,

Norwich NR4 7UH, UK.

Keywords: sugar nucleotide, glycosyl-1-phosphate, mannuronate, pyrophosphorylation, alginate

\section{Introduction}

Alginate is a heterogenous polysaccharide composed of $\beta$-1,4-linked D-mannuronic acid (M) and its C5 epimer $\alpha$-L-guluronic acid (G) (Figure la). Within alginate sub-structure the relative proportions of $\mathrm{M}$ and $\mathrm{G}$ units, their homo- or heteropolymeric block-groupings and the possibility for acetylation at the $\mathrm{C} 2$ and/or $\mathrm{C} 3$ positions of $\mathrm{M}$ residues produces a structurally diverse biopolymer. This structural microheterogeneity varies depending on the alginate source and the biopolymer is produced by both plants and bacteria. The study of alginate biochemistry and biosynthesis has largely focused on the bacterial genera Pseudomonas, owing to the prevalence of the opportunistic human pathogen Pseudomonas aeruginosa, which causes chronic infections in cystic fibrosis patients, contributing to a reduction in lung function and increased mortality rates. ${ }^{1}$ Alginate is also an important industrial biomaterial, currently sourced from marine algae and utilised as a stabiliser, viscosifier and gelling agent in the food, beverage, paper and pharmaceutical industries. ${ }^{2}$

Alginate biosynthesis utilises the sugar nucleotide GDP-D-ManA, 1 (Figure 1b), which is sourced from the cytosolic metabolic pool through a series of enzymatic transformations starting from fructose 6-phosphate and ultimately obtained via oxidation of GDP-D-Man to the uronate by GDP-mannose dehydrogenase (GMD). ${ }^{3}$ Following this, an intricate, multi-enzyme mediated polymerisation process assembles the $\beta$-D-mannuronate polymer, which is then further modified by epimerisation, acetylation and truncation before export.
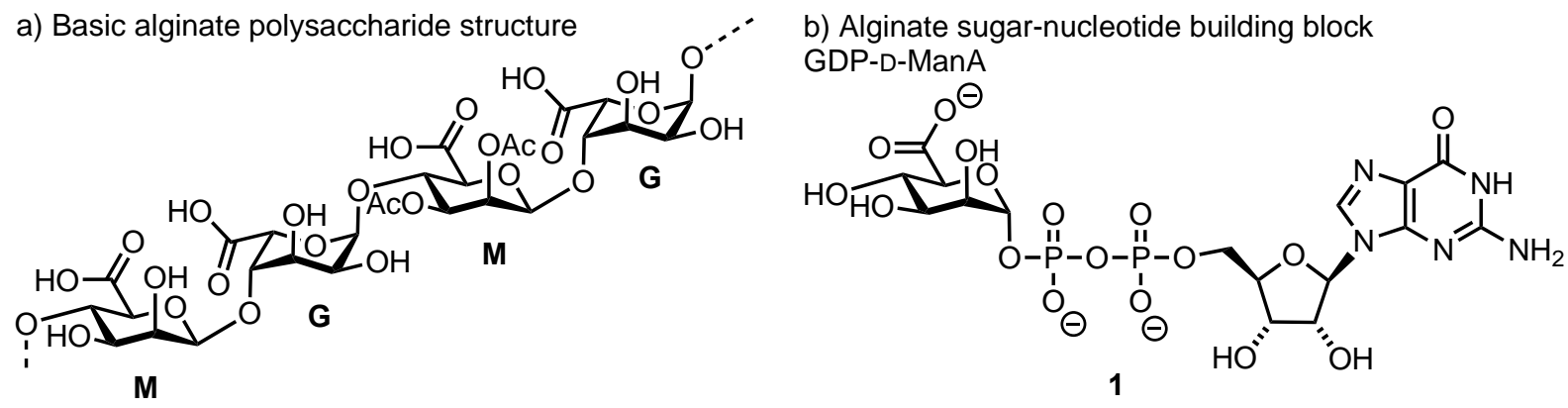

Figure 1. a) Chemical structure of alginate showing constituent $M / G$ residues and $C 2 / C 3$ acetylation for one $M$ residue, b) GDP-D-ManA 1, the sugar nucleotide building block of alginate. 
As part of a program to investigate the enzymes involved in the biosynthesis of alginate, ${ }^{4}$ were interested to chemically synthesise $\mathbf{1}$ and deliver an enabling sugar nucleotide tool to support elucidation of the alginate polymerisation process. A chemical synthesis of $\mathbf{1}$ was recently completed by Codée et $a l^{5}$ using $\mathrm{P}^{\mathrm{III}}$-amidite- $\mathrm{P}^{\mathrm{V}}$ chemistry to accomplish the key pyrophosporylation step in forming $\mathbf{1}$. Herein we report our approach to $\mathbf{1}$, instead using a $\mathrm{P}^{\mathrm{V}}-\mathrm{P}^{\mathrm{V}}$ pyrophosphorylation and present the results of evaluating two differentially protected D-ManA 1-phosphates for coupling. Alongside this we evaluated an enzymatic approach to 1 from GDP-D-Man using recombinant GMD from P. aeruginosa.

\section{Results and Discussion}

\subsection{Synthesis of D-ManA 1-phosphates}

Enzymatic and chemical approaches to synthesise uronic acid 1-phosphates have been explored ${ }^{6,7}$ From a chemical perspective, the inclusion of an acidic, charged functional group in pyrophosphorylative coupling is challenging and efforts to circumvent this have involved completing late-stage (post-diphosphate formation) oxidation to the uronate ${ }^{8}$ and protecting the carboxylate. ${ }^{9}$ We first sought to synthesise two differentially protected D-ManA 1phosphates, $\mathbf{7}$ and $\mathbf{8}$, as we wanted to examine the effect of retaining a protected carboxylate group (against the free acid form) when completing chemical pyrophosphorylation. Previously it was noted by Linhardt ${ }^{9}$ that retaining a methyl ester protecting group (for their synthesis of UDP-L-IdoA) avoided problems during the pyrophosphorylation coupling reaction (65\% reported yield). However, the synthesis of the related UDP-D-GlcA reported by Khorana ${ }^{10}$ using free D-GlcA 1-phosphate indicated an equally successful approach $(66 \%$ yield).

Our synthetic route began from mannuronic acid derivative 2 , for which we recently reported a multi-gram scale synthesis. ${ }^{11}$ Methylation of $\mathbf{2}$ was achieved using iodomethane and $\mathrm{K}_{2} \mathrm{CO}_{3}$ to give ester 3 in good yield (77\%, Scheme 1). We next evaluated MacDonald's conditions $\left(\mathrm{H}_{3} \mathrm{PO}_{4(\mathrm{~s})} \text {, high vacuum and } 60{ }^{\circ} \mathrm{C}\right)^{12}$ to directly form glycosyl 1-phosphates from 2 and 3. Unfortunately, in our hands, 2 and $\mathbf{3}$ largely decomposed under the reaction conditions or formed significant amounts of the C4-C5 elimination product and we instead attempted to access thioglycoside donor $\mathbf{4}$, as a means to provide protected mannuronate 1-phosphate $\mathbf{6}$. We found the reaction to form $\mathbf{4}$ from $\mathbf{3}$ to be sluggish and low-yielding, with significant amounts of orthoester formation observed. This was attributed to the disarming nature of the uronate and use of acetate protecting groups. ${ }^{13} \mathrm{We}$ were able to optimise this reaction using TMSOTf as a Lewis acid $\left(\mathrm{BF}_{3} \mathrm{Et}_{2} \mathrm{O}\right.$ showed no reaction) to a yield of $63 \%(5: 1 \alpha / \beta$ ratio of 4 with 4:1 $\alpha$ /orthoester, as judged by ${ }^{1} \mathrm{H}$ NMR) using a reaction temperature of $-15{ }^{\circ} \mathrm{C}$ for $6 \mathrm{~h}$. Raising the temperature to $0{ }^{\circ} \mathrm{C}$ and extending the reaction time to $32 \mathrm{~h}$ caused a significant reduction in yield $(17 \%$, with $20 \%$ returned 3$)$, but did reduce orthoester formation $(6: 1 \alpha / \beta$ ratio of 4 with 33:1 $\alpha$ /orthoester). With amounts of pure 4 in hand, following silica gel chromatography, we next converted to the protected 1-phosphate $\mathbf{6}$ using dibenzyl phosphate (DBP) under standard thioglycoside activation conditions. This afforded $\mathbf{6}$, albeit in low yield (23\%), but with the expected ${ }^{31} \mathrm{P}$ NMR resonance for the anomeric phosphate $(-3.24 \mathrm{ppm})$ and the characteristic doublet of doublets for $\mathrm{H}_{1}\left({ }^{3} J_{\mathrm{H} 1-31 \mathrm{P}}=6.4 \mathrm{~Hz},{ }^{3} J_{\mathrm{H} 1-\mathrm{H} 2}=1.9 \mathrm{~Hz}\right)$. 


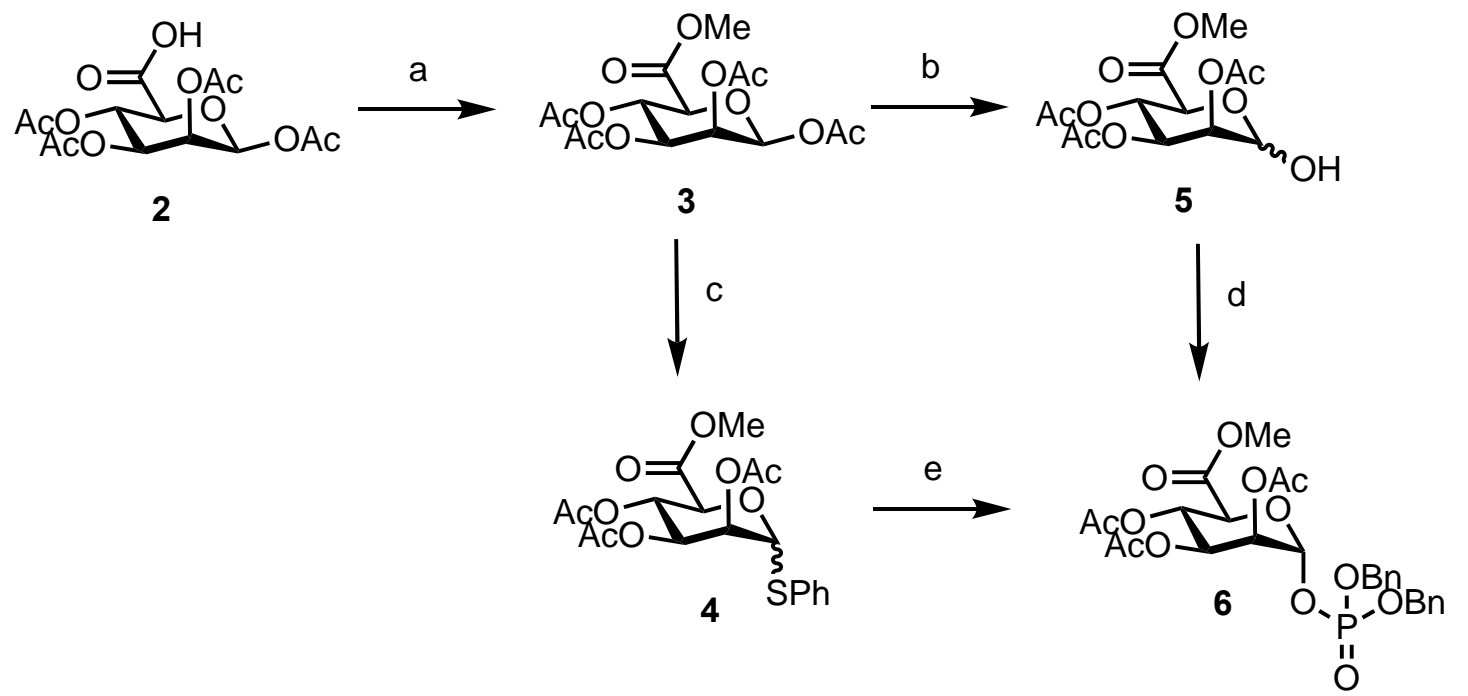

Scheme 1. Synthesis of protected D-ManA 1-phosphate 6. a) $\mathrm{MeI}, \mathrm{K}_{2} \mathrm{CO}_{3}, \mathrm{DMF}, 77 \%$ b) $\mathrm{NH}_{2}-\mathrm{NH}_{2} \mathrm{AcOH}, \mathrm{DMF}$, $68 \%$ c) TMSOTf, $\mathrm{HSPh}, \mathrm{DCM}, 63 \%$ d) i) $\mathrm{Cl}_{3} C C N, \mathrm{~K}_{2} \mathrm{CO}_{3}, \mathrm{DCM}, 88 \%$ ii) $\mathrm{HO}-\mathrm{P}(\mathrm{O})(\mathrm{OBn})_{2}, \mathrm{TMSOTf}$, DCM, $49 \%$ e) $\mathrm{HO}-\mathrm{P}(\mathrm{O})(\mathrm{OBn})_{2}$, NIS, AgOTf, DCM, $23 \%$.

Owing to the problems we encountered in accessing 6 via 4 (15\%, 2 steps), we explored an alternative route, firstly removing the anomeric acetate from $\mathbf{3}$ to give hemiacetal $\mathbf{5}$, in $68 \%$ yield, followed by conversion to a trichloroacetimidate donor ( $88 \%$ yield) and immediate reaction with DBP using TMSOTf as promoter. Although successful, our attempts at optimisation did not deliver $\mathbf{6}$ in a yield greater than $49 \%$ (from 5), but did afford the material in 30\% overall yield from 3, double that observed for the route from 4.

We next undertook a two-stage deprotection of $\mathbf{6}$ to deliver D-ManA 1-phosphates 7 and $\mathbf{8}$ (Scheme 2). We removed the phosphate benzyl protecting groups using hydrogenolysis, followed by conversion to a bis-triethylammonium salt, delivering semi-protected phosphate 7 in very good yield (71\%). The acetate protecting groups of 7 were then cleaved to give DManA 1-phosphate 8. At this juncture we re-visited the Macdonald phosphorylation and were able to establish conditions to afford $\mathbf{8}$ directly from D-mannose 9 (Scheme 2). Following peracetylation and anomeric phosphorylation, ${ }^{14}$ the crude 1-phosphate could be conveniently oxidised using TEMPO/BAIB or TEMPO/ $\mathrm{NaOCl}^{15}$ to deliver 8 in $15 \%$ yield over three steps. This compares to an overall yield of $15 \%$ over 5 steps for the route to $\mathbf{8}$ from $\mathbf{2}$, which whilst longer, did afford access to the partially protected 1-phosphate 7. With differentially protected D-ManA 1-phosphates, $\mathbf{7}$ and $\mathbf{8}$, in hand we next evaluated their pyrophosphorylative coupling (with GMP-morpholidate) to deliver $\mathbf{1}$.

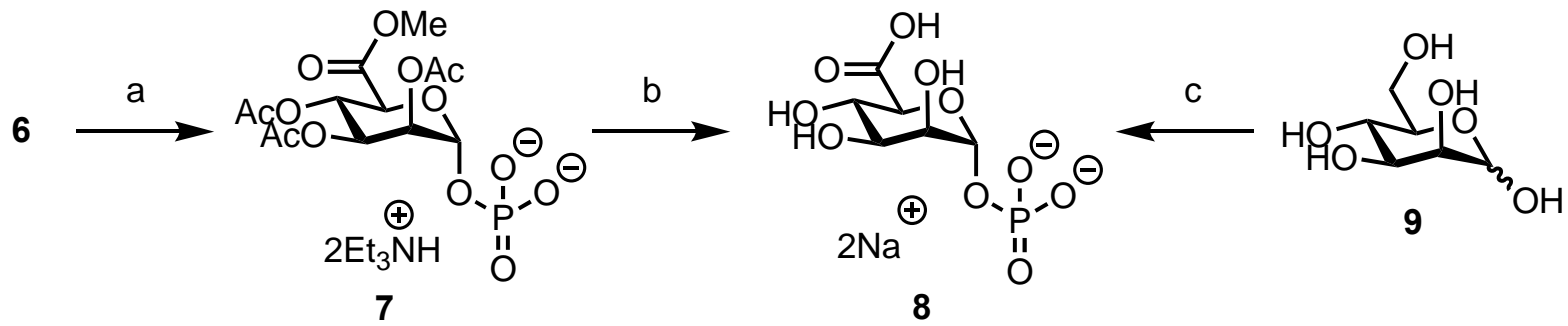

Scheme 2. Synthesis of semi-protected and free D-ManA 1-phosphates 7 and 8. a) $\mathrm{H}_{2}, \mathrm{Pd} / \mathrm{C}, \mathrm{MeOH}, \mathrm{Et}_{3} \mathrm{~N}, 71 \%$; b) $\mathrm{Et}_{3} \mathrm{~N} / \mathrm{MeOH} / \mathrm{H}_{2} \mathrm{O}, 2: 2: 1, \mathrm{IR} 120 \mathrm{Na}^{+}$resin, 96\%; c) i) $\mathrm{Ac}{ }_{2} \mathrm{O}$, pyridine, DMAP, 93\% ii) $\mathrm{H}_{3} \mathrm{PO}_{4}$, then $\mathrm{LiOH}$, $56 \%$ iii) TEMPO, BAIB, $\mathrm{H}_{2} \mathrm{O} / \mathrm{MeCN}, 30 \%$ or TEMPO, $\mathrm{NaOCl}, \mathrm{NaOH}, \mathrm{H}_{2} \mathrm{O} / \mathrm{MeCN}, 21 \%$. 


\subsection{Chemical Synthesis of GDP-D-ManA}

In recent years, chemical approaches to synthesise sugar nucleotides have favoured $\mathrm{P}^{\mathrm{V}}-\mathrm{P}^{\mathrm{V}}$ and $\mathrm{P}^{\mathrm{V}}-\mathrm{P}^{\mathrm{III}}$ pyrophosphorylation methods, removing any anomeric integrity consequences of glycosylating a nucleoside diphosphate. ${ }^{16,17}$ We selected a $\mathrm{P}^{\mathrm{V}}-\mathrm{P}^{\mathrm{V}}$ approach using GMP-morpholidate as the coupling partner for $\mathbf{7}$ or $\mathbf{8}$ and trialled different activators, solvents and durations, the results of which are summarised in Table 1.

Table 1. Evaluation of pyrophosphorylation conditions to synthesise 1.

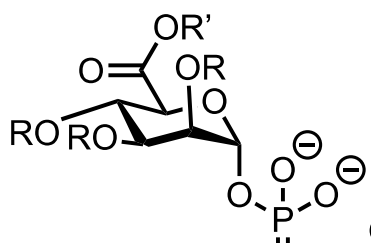

i) Pyrophosphorylation (see table)

ii) Deprotection

(when using 7)

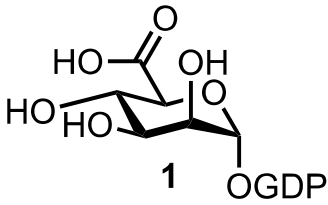

7 or $8 \stackrel{\oplus}{\text { OI } 2 \mathrm{Et}_{3} \mathrm{NH}}$

\begin{tabular}{|c|c|c|c|c|c|c|}
\hline Entry & 1-phosphate & $\begin{array}{l}\text { Additive } \\
(\text { equiv. })^{\mathfrak{f}}\end{array}$ & $\begin{array}{c}\text { Reaction } \\
\text { Time (h) }\end{array}$ & $\begin{array}{l}\text { Solvent } \\
(\text { conc. })\end{array}$ & $\begin{array}{l}\text { Yield } \\
(\%)\end{array}$ & Notes \\
\hline 1 & $\mathbf{N}$ & $\mathbf{M I C}(2.9)$ & 60 & $\begin{array}{c}\text { DMF } \\
(0.06)\end{array}$ & 0 & No rxn. \\
\hline 2 & $\mathbf{7}$ & $\begin{array}{c}\text { DCI } \\
(4.0)\end{array}$ & 56 & $\begin{array}{c}\text { DMF } \\
(0.05)\end{array}$ & $<5^{\$}$ & $\begin{array}{c}\text { DCI } \\
\text { contamination }\end{array}$ \\
\hline 3 & 7 & $\begin{array}{c}\text { DCI } \\
(1.0)\end{array}$ & 108 & $\begin{array}{c}\text { DMF } \\
(0.05)\end{array}$ & $<5^{\$}$ & Reduced DCI \\
\hline 4 & 7 & $\begin{array}{c}\text { None then DCI } \\
(1.0)\end{array}$ & $144^{\wedge}$ & $\begin{array}{c}\text { Pyr. } \\
(0.06)\end{array}$ & $22^{\$}$ & Reduced DCI \\
\hline 5 & 7 & $\begin{array}{c}\text { DCI } \\
(1.0)\end{array}$ & 120 & $\begin{array}{c}\text { Pyr. } \\
(0.06)\end{array}$ & $46^{\$}$ & Reduced DCI \\
\hline 6 & $\mathbf{8}$ & $\begin{array}{c}\text { DCI } \\
(1.0)\end{array}$ & 40 & $\begin{array}{c}\text { DMF } \\
(0.07)\end{array}$ & 0 & No rxn. \\
\hline 7 & $\mathbf{8}$ & None & 144 & $\begin{array}{c}\text { Pyr. } \\
(0.04)\end{array}$ & 0 & No rxn. \\
\hline
\end{tabular}

falong with 1.5 equiv. GMP-morpholidate and 1.0 equiv. of 1-phosphate.

${ }^{\$}$ following deprotection of the crude coupling reaction $\left(\mathrm{Et}_{3} \mathrm{~N}, \mathrm{MeOH}, \mathrm{H}_{2} \mathrm{O}\right)$.

${ }^{\wedge}$ DCI was added after $48 \mathrm{~h}$, as no reaction was indicated to have taken place by TLC.

$\mathrm{R}=\mathrm{Ac}, \mathrm{R}^{\prime}=\mathrm{Me}$.

$N$-Methylimidazole hydrochloride $\left(N\right.$-MIC ${ }^{18}$, Table 1 , entry 1$)$ has been reported as a superior pyrophosphorylative catalyst to the traditional use of $1-H$-tetrazole. Utilising it here, we were unable to detect the formation of $\mathbf{1}$ by TLC (isopropyl alcohol/ammonium hydroxide/water, 6:3:1) and observed baseline material after $60 \mathrm{~h}$. Repeating the reaction (including several co-evaporations with toluene under $\mathrm{N}_{2}$ prior to reaction) led to similar outcomes and we thus switched to using 4,5-dicyanoimidazole (DCI, Table 1, entry 2). The reaction proceeded smoothly over $56 \mathrm{~h}$ with TLC analysis indicating significant consumption of 7 and crude ${ }^{31} \mathrm{P}$ NMR confirming nucleoside diphosphate formation $\left(\delta_{\mathrm{P}}-11.4,-14.5 \mathrm{ppm}\right)$. The crude material isolated was immediately subjected to pyranoside deprotection using $\mathrm{Et}_{3} \mathrm{~N} / \mathrm{MeOH} / \mathrm{H}_{2} \mathrm{O}$ followed by strong-anion exchange (SAX) purification which delivered $\mathbf{1}$ but only in very poor yields $(<5 \%)$. We encountered problems here during SAX purification, namely that the large amount of DCI used (4.0 equiv.) co-eluted with 1 , thus requiring additional $\mathrm{C} 18$ reverse phase purification to remove this impurity which reduced the overall yield. In order to solve these problematic final purification(s) we investigated reducing the equivalents of DCI alongside changing the reaction solvent to pyridine (Table 1, entries 3 and 
4). Pleasingly, we were able to improve the yield of 1 to $46 \%$ using 1.0 equiv. of DCI in pyridine (Table 1 entry 5). We also observed that the uncatalysed reaction was very slow (no reaction after $48 \mathrm{~h}$ ), but did not investigate reducing the amount of DCI further. Using only 1.0 equivalent of DCI we were also able to return to using DMF as solvent, which improved solubility of the reagents slightly, obtaining similar results to those using pyridine.

For ManA 1-phosphate 8 we observed no indicative conversion to 1 by TLC (Table 1, entry 6) and we surmised that poor solubility of the components was hindering the reaction in DMF. Changing solvent to pyridine (Table 1, entry 7) unfortunately had no positive effect on the reaction outcome and we concluded that the material was not reacting under the conditions tried (GMP-morpholidate could still be observed by crude ${ }^{31} \mathrm{P}$ NMR). In summary, we observed that successful pyrophosphorylative coupling to form 1 could best be achieved using carboxylate protected mannuronate 1-phosphate 7. The chemical synthesis route developed here delivers multi-milligram access to $\mathbf{1}$ in five steps and $8 \%$ overall yield from 2. Whilst more involved than the direct enzymatic option considered below, this methodology will be underpinning to the development of analogues syntheses derived from $\mathbf{1}$, which is essential to the continued study of sugar-nucleotide-mediated alginate biosynthesis.

\subsection{Enzymatic Synthesis of GDP-D-ManA}

Within alginate biosynthesis, $\mathbf{1}$ is produced by dehydrogenative oxidation of GDP-DMan by GMD. In order to investigate enzymatic production of 1 we incubated GDP-D-Man with recombinant GMD from $P$. aeruginosa in the presence of $\mathrm{NAD}^{+}$at room temperature with gentle shaking. The reaction was monitored by strong anion exchange chromatography at different time points. After $21 \mathrm{~h}$, the conversion of GDP-D-Man to 1 reached $70 \%$ using 2 equivalents of $\mathrm{NAD}^{+}$and enabled the isolation of $\mathrm{mg}$ quantities of the desired material (Scheme 3). After $72 \mathrm{~h}$, complete consumption of the starting material was evident, following the addition of four further equivalents of $\mathrm{NAD}^{+}$(see SI).

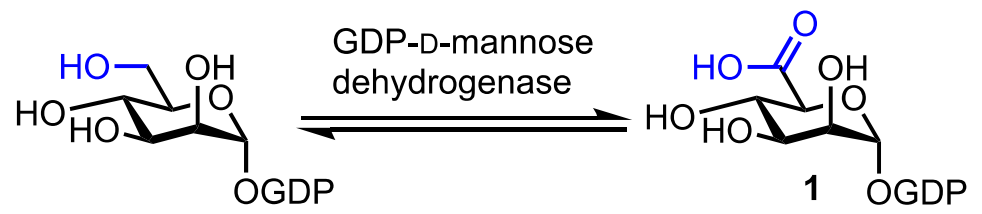

Scheme 3. Enzymatic synthesis of 1 from GDP-D-Man. a) $\mathrm{NAD}^{+}, \mathrm{DTT}, \mathrm{MgCl}_{2}, \mathrm{pH} 7.4,70 \%$.

\section{Conclusion}

We have established chemical $\left(\mathrm{P}^{\mathrm{V}}-\mathrm{P}^{\mathrm{V}}\right)$ and enzymatic routes to the alginate sugar nucleotide feedstock GDP-D-ManA. Synthetic access to partially protected and fully deprotected anomeric 1-phosphates of D-mannuronic acid enabled their evaluation in pyrophosphorylative coupling to the target nucleoside diphosphate. Only the partially protected glycosyl 1-phosphate was effective for this reaction under the conditions examined. This procedure is complimented by an enzymatic approach to the same sugar nucleotide using the GDP-D-mannose dehydrogenase from P. aeruginosa.

\section{Experimental section}

\subsection{General Methods and Materials}

All reagents and solvents which were available commercially were purchased from Acros, Alfa Aesar, Fisher Scientific, or Sigma Aldrich. All reactions in non-aqueous solvents were conducted in oven dried glassware under a nitrogen atmosphere with a magnetic stirring device. Solvents were purified by passing through activated alumina columns and used 
directly from a Pure Solv-MD solvent purification system and were transferred under nitrogen. Reactions requiring low temperatures used the following cooling baths: $-78{ }^{\circ} \mathrm{C}$ (dry ice/acetone), $-30{ }^{\circ} \mathrm{C}$ (dry ice/acetone), $-15{ }^{\circ} \mathrm{C}\left(\mathrm{NaCl} /\right.$ ice/water) and $0{ }^{\circ} \mathrm{C}$ (ice/ water). Infrared spectra were recorded neat on a Perkin Elmer Spectrum 100 FT-IR spectrometer; selected absorbtion frequencies ( $\mathrm{vmax}$ ) are reported in $\mathrm{cm}^{-1} .{ }^{1} \mathrm{H}$ NMR spectra were recorded at 400 $\mathrm{MHz}$ and ${ }^{13} \mathrm{C}$ spectra at $100 \mathrm{MHz}$ respectively using a Bruker AVIII400 spectrometer. ${ }^{1} \mathrm{H}$ NMR signals were assigned with the aid of gDQCOSY. ${ }^{13} \mathrm{C}$ NMR signals were assigned with the aid of gHSQCAD. Coupling constants are reported in Hertz. Chemical shifts $(\delta$, in ppm) are standardised against the deuterated solvent peak. NMR data were analysed using Nucleomatica iNMR or Mestrenova software. ${ }^{1} \mathrm{H}$ NMR splitting patterns were assigned as follows: br s (broad singlet), s (singlet), d (doublet), app. t (apparent triplet), $\mathrm{t}$ (triplet), dd (doublet of doublets), ddd (doublet of doublet of doublets), or m (multiplet and/or multiple resonances). Reactions were followed by thin layer chromatography (TLC) using Merck silica gel 60F254 analytical plates (aluminium support) and were developed using standard visualising agents: short wave UV radiation $(245 \mathrm{~nm})$ and $5 \%$ sulfuric acid in methanol/ $\Delta$. Purification via flash column chromatography was conducted using silica gel $60(0.043-0.063$ $\mathrm{mm})$. Melting points were recorded using open glass capillaries on a Gallenkamp melting point apparatus and are uncorrected. Optical activities were recorded on automatic polarimeter Rudolph autopol I or Bellingham and Stanley ADP430 (concentration in $\mathrm{g} / 100 \mathrm{~mL}) \cdot \mathrm{pH}$ measurements were recorded using a Hanna ${ }^{\circledR} \mathrm{pH} 20$ meter. MS and HRMS (ESI) were obtained on Waters (Xevo, G2-XS TOF) or Waters Micromass LCT spectrometers using a methanol mobile phase. High resolution (ESI) spectra were obtained on a Xevo, G2-XS TOF mass spectrometer. HRMS was obtained using a lock-mass to adjust the calibrated mass. HPLC was performed on an Agilent Technologies 1200 series machine, using a Waters Bridge Reversed-phase prep-C18 column $(5 \mu \mathrm{m}$ OBD, $19 \times 100 \mathrm{~mm})$. $\mathrm{MeCN}: \mathrm{H} 2 \mathrm{O}, 60: 40 \rightarrow 100 \%$ was used as a mobile phase and the product was detected using $\mathrm{UV}$ at $254 \mathrm{~nm}$. Purification by $\mathrm{C} 18$ chromatography was conducted using a Thermoscientific X30 SPE column (HyperSep C18, $6 \mathrm{~mL}$ ) eluting with $\mathrm{H}_{2} \mathrm{O}$. Purification via ion exchange chromatography was conducted on Bio-Rad Biologic LP system using a Bio-Scale Mini UNOsphere Q (strong anion exchange) cartridge $(5 \mathrm{~mL})$ : flow rate $(3.0 \mathrm{~mL} / \mathrm{min}), 0 \rightarrow 100 \%$ $1.0 \mathrm{M}\left(\mathrm{NH}_{4}\right) \mathrm{HCO}_{3}$ over 33 min or strong anion-exchange (SAX) HPLC on Poros HQ 50 was performed as published earlier. ${ }^{19}$

\subsection{Methyl (1,2,3,4-tetra-O-acetyl- $\beta$-D-mannopyranosyluronate (3)}

To a stirred solution of 1,2,3,4-tetra- $O$-acetyl- $\beta$-D-mannuronic acid $2^{11}(600 \mathrm{mg}, 1.70 \mathrm{mmol}$, 1.0 equiv. $)$ in anhydrous dimethylformamide $(8 \mathrm{~mL})$ was added methyl iodide $(250 \mu \mathrm{L}, 4.02$ mmol, 2.4 equiv.) and $\mathrm{K}_{2} \mathrm{CO}_{3}(156 \mathrm{mg}, 1.13 \mathrm{mmol}, 1.5$ equiv.). The solution was stirred at room temperature for $72 \mathrm{~h}$, whereupon TLC analysis (hexane/ethyl acetate, 3/1) indicated complete conversion of starting material to a higher $\mathrm{R}_{\mathrm{f}}$ spot. The reaction was quenched with methanol $(5 \mathrm{~mL})$, ethyl acetate $(25 \mathrm{~mL})$ was added and the solution washed with $\mathrm{H}_{2} \mathrm{O}(15$ $\mathrm{mL})$. The aqueous layer was extracted with ethyl acetate $(25 \mathrm{~mL})$, the combined organic layers washed with water $(15 \mathrm{~mL})$ and brine $(15 \mathrm{~mL})$, dried $\left(\mathrm{MgSO}_{4}\right)$, filtered and concentrated in vacuo. The resultant yellow solid was triturated with methanol to afford $\mathbf{2}$ as a white solid (480 mg, $1.3 \mathrm{mmol}, 77 \%)$. $\mathrm{R}_{\mathrm{f}} 0.23$ (hexane/ethyl acetate, $\left.3 / 1\right) ;[\alpha]_{D}^{26}=-16.0(c=$ $\left.0.5, \mathrm{CHCl}_{3}\right) ;{ }^{1} \mathrm{H} \mathrm{NMR}\left(300 \mathrm{MHz}, \mathrm{CDCl}_{3}\right) \boldsymbol{\delta}_{\mathrm{H}} 5.91\left(1 \mathrm{H}, \mathrm{d}, J=1.3 \mathrm{~Hz}, \mathrm{H}_{1}\right), 5.50(1 \mathrm{H}, \mathrm{dd}, J=$ $\left.3.5,1.2 \mathrm{~Hz}, \mathrm{H}_{2}\right), 5.42\left(1 \mathrm{H}, \mathrm{t}, J=9.4 \mathrm{~Hz}, \mathrm{H}_{4}\right), 5.19\left(1 \mathrm{H}, \mathrm{dd}, J=9.6,3.2 \mathrm{~Hz}, \mathrm{H}_{3}\right), 4.15(1 \mathrm{H}, \mathrm{d}, J$ $\left.=9.4 \mathrm{~Hz}, \mathrm{H}_{5}\right), 3.74\left(3 \mathrm{H}, \mathrm{s}, \mathrm{C}(\mathrm{O}) \mathrm{OCH}_{3}\right), 2.21\left(3 \mathrm{H}, \mathrm{s}, \mathrm{C}(\mathrm{O}) \mathrm{CH}_{3}\right), 2.12\left(3 \mathrm{H}, \mathrm{s}, \mathrm{C}(\mathrm{O}) \mathrm{CH}_{3}\right), 2.07$ $\left(3 \mathrm{H}, \mathrm{s}, \mathrm{C}(\mathrm{O}) \mathrm{CH}_{3}\right), 2.03\left(3 \mathrm{H}, \mathrm{s}, \mathrm{C}(\mathrm{O}) \mathrm{CH}_{3}\right) ;{ }^{13} \mathrm{C} \mathrm{NMR}\left(100 \mathrm{MHz}, \mathrm{CDCl}_{3}\right) \boldsymbol{\delta}_{\mathrm{C}} 170.6(\mathrm{C}=\mathrm{O})$, $170.0(2 \times \mathrm{C}=\mathrm{O}), 168.8(\mathrm{C}=\mathrm{O}), 167.2(\mathrm{C}=\mathrm{O}), 90.1\left(\mathrm{C}_{1}\right), 73.6\left(\mathrm{C}_{5}\right), 70.0\left(\mathrm{C}_{3}\right), 67.8\left(\mathrm{C}_{2}\right), 66.7$ 
$\left(\mathrm{C}_{4}\right), 53.3\left(\mathrm{CO}_{2} \mathrm{CH}_{3}\right), 21.1\left(\mathrm{C}(\mathrm{O}) \mathrm{CH}_{3}\right), 21.1\left(\mathrm{C}(\mathrm{O}) \mathrm{CH}_{3}\right), 21.0\left(\mathrm{C}(\mathrm{O}) \mathrm{CH}_{3}\right), 20.9\left(\mathrm{C}(\mathrm{O}) \mathrm{CH}_{3}\right)$; HRMS [M+NH$]^{+}$calculated for $\mathrm{C}_{15} \mathrm{H}_{24} \mathrm{O}_{11} \mathrm{~N}$ : 394.1344; found: 394.1337.

4.3 Methyl (phenyl-2,3,4-tri-O-acetyl-1-thio- $\alpha / \beta$-D-mannopyranosyl)uronate (4) Uronate 3 (200 mg, $500 \mu \mathrm{mol}, 1.0$ equiv.) and powdered $4 \AA$ molecular sieves were dissolved in anhydrous dichloromethane $(3 \mathrm{~mL})$ and stirred under $\mathrm{N}_{2}$ atmosphere for $12 \mathrm{~h}$. Thiophenol (82 $\mu \mathrm{L}, 820 \mu$ mol. 1.5 equiv.) was added, the solution cooled to $-15{ }^{\circ} \mathrm{C}$ and TMSOTf $(0.30$ $\mathrm{mL}, 1.62 \mathrm{mmol}, 3$ equiv.) was added dropwise. The reaction mixture was stirred at $-15{ }^{\circ} \mathrm{C}$ for $6 \mathrm{~h}$, whereupon TLC analysis (hexane/ethyl acetate 3/1) showed complete conversion of the starting material to a higher $\mathrm{R}_{\mathrm{f}}$ spot. The yellow reaction mixture was quenched through the addition of triethylamine until $\mathrm{pH}=7$, filtered over Celite ${ }^{\mathrm{TM}}$ and diluted with dichloromethane $(25 \mathrm{~mL})$. The organic layer was washed with distilled water $(15 \mathrm{~mL})$ and brine $(15 \mathrm{~mL})$, dried $\left(\mathrm{MgSO}_{4}\right)$, filtered and concentrated under reduced pressure to afford a pale-yellow oil. Purification by silica column chromatography, eluting with hexane/ethyl acetate $(1 / 0,3 / 1)$ afforded 4 as an opaque, colourless oil (134 mg, $315 \mu \mathrm{mol}, 63 \%) . \mathrm{R}_{\mathrm{f}} 0.30$ (hexane/ethyl acetate 3/1); ${ }^{1} \mathrm{H}$ NMR $\left(400 \mathrm{MHz}, \mathrm{CDCl}_{3}\right) \boldsymbol{\delta}_{\mathrm{H}} \alpha$-anomer $7.51(2 \mathrm{H}, \mathrm{d}, J=6.6 \mathrm{~Hz}$, Ar- $H), 7.30(3 \mathrm{H}, \mathrm{m}, \mathrm{Ar}-H), 5.59\left(1 \mathrm{H}, \mathrm{d}, J=3.8 \mathrm{~Hz}, \mathrm{H}_{1}\right), 5.48-5.40\left(2 \mathrm{H}, \mathrm{m}, \mathrm{H}_{2}, \mathrm{H}_{4}\right), 5.33$ $\left(1 \mathrm{H}, \mathrm{dd}, J=8.4,3.1 \mathrm{~Hz}, \mathrm{H}_{3}\right), 4.79\left(1 \mathrm{H}, \mathrm{d}, J=7.8 \mathrm{~Hz}, \mathrm{H}_{5}\right), 3.76\left(3 \mathrm{H}, \mathrm{s}, \mathrm{C}(\mathrm{O}) \mathrm{OCH}_{3}\right), 2.11$ $\left(3 \mathrm{H}, \mathrm{s}, \mathrm{C}(\mathrm{O}) \mathrm{CH}_{3}\right), 2.08\left(3 \mathrm{H}, \mathrm{s}, \mathrm{C}(\mathrm{O}) \mathrm{CH}_{3}\right), 2.02\left(3 \mathrm{H}, \mathrm{s}, \mathrm{C}(\mathrm{O}) \mathrm{CH}_{3}\right) ;{ }^{13} \mathrm{C} \mathrm{NMR}(100 \mathrm{MHz}$, $\left.\mathrm{CDCl}_{3}\right) \boldsymbol{\delta}_{\mathrm{C}} 169.7(\mathrm{C}=\mathrm{O}), 169.5(\mathrm{C}=\mathrm{O}), 169.3(\mathrm{C}=\mathrm{O}), 167.8(\mathrm{C}=\mathrm{O}), 132.3(\mathrm{Ar}-\mathrm{C}), 131.7(\mathrm{Ar}-$ $C), 129.1(\mathrm{Ar}-C), 128.0(\mathrm{Ar}-C), 84.4\left(\mathrm{C}_{1}\right), 71.0\left(\mathrm{C}_{5}\right), 69.2\left(\mathrm{C}_{2}\right), 68.3\left(\mathrm{C}_{3}\right), 67.4\left(\mathrm{C}_{4}\right), 52.6$ $\left(C(\mathrm{O}) \mathrm{OCH}_{3}\right), 20.7\left(\mathrm{C}(\mathrm{O}) \mathrm{CH}_{3}\right), 20.6\left(\mathrm{C}(\mathrm{O}) C \mathrm{H}_{3}\right),\left(\mathrm{C}(\mathrm{O}) C_{3}\right) 20.5\left(\mathrm{C}(\mathrm{O}) C_{3} \mathrm{H}_{3}\right) ; H R M S$ $\left[\mathrm{M}+\mathrm{NH}_{4}\right]^{+}$calculated for $\mathrm{C}_{19} \mathrm{H}_{26} \mathrm{O}_{9} \mathrm{SN}$ : 444.1323; found: 444.1323 .

\subsection{Methyl 2,3,4-tri-O-acetyl- $\alpha$-D-mannopyranosyluronate (5)}

To a stirred solution of 3 (100 mg, $0.27 \mathrm{mmol}, 1.0$ equiv.) in anhydrous DMF (2 mL) was added hydrazine acetate ( $38 \mathrm{mg}, 0.41 \mathrm{mmol}, 1.5$ equiv.). The solution was stirred at room temperature for $3 \mathrm{~h}$, whereupon TLC analysis (hexane/ethyl acetate, 1/1) indicated complete conversion of starting material to a lower $\mathrm{R}_{\mathrm{f}}$ spot. The solvent was removed in vacuo and the residue dissolved in ethyl acetate $(10 \mathrm{~mL})$. The organic layer was washed with distilled water $(10 \mathrm{~mL})$ and the aqueous layer re-extracted with ethyl acetate $(10 \mathrm{~mL})$. The combined organic layers were washed with distilled water $(20 \mathrm{~mL})$, dried $\left(\mathrm{MgSO}_{4}\right)$, filtered and concentrated in vacuo. Purification by silica gel column chromatography eluting with hexane/ethyl acetate $(3 / 1,1 / 1)$ afforded 5 as a colourless oil $(95 \% \alpha$-anomer, $58 \mathrm{mg}, 0.17$ mmol, 64\%). $\mathrm{R}_{\mathrm{f}} 0.47$ (hexane/ethyl acetate, $\left.1 / 1\right) ;{ }^{1} \mathrm{H} \mathrm{NMR}\left(400 \mathrm{MHz}, \mathrm{CDCl}_{3}\right) \boldsymbol{\delta}_{\mathrm{H}} \alpha$-anomer $5.45\left(1 \mathrm{H}, \mathrm{d}, J=3.2 \mathrm{~Hz}, \mathrm{H}_{3}\right), 5.41\left(1 \mathrm{H}, \mathrm{d}, J=9.0 \mathrm{~Hz}, \mathrm{H}_{4}\right), 5.34\left(1 \mathrm{H}, \mathrm{d}, J=2.5 \mathrm{~Hz}, \mathrm{H}_{1}\right), 5.26-$ $5.25\left(1 \mathrm{H}, \mathrm{m}, \mathrm{H}_{2}\right), 4.58\left(1 \mathrm{H}, \mathrm{d}, J=8.9 \mathrm{~Hz}, \mathrm{H}_{5}\right), 2.15\left(3 \mathrm{H}, \mathrm{s}, \mathrm{C}(\mathrm{O}) \mathrm{OCH}_{3}\right), 2.07(3 \mathrm{H}, \mathrm{s}$, $\left.\mathrm{C}(\mathrm{O}) \mathrm{OCH}_{3}\right), 2.02\left(3 \mathrm{H}, \mathrm{s}, \mathrm{C}(\mathrm{O}) \mathrm{OCH}_{3}\right) ;{ }^{13} \mathrm{C} \mathrm{NMR}\left(100 \mathrm{MHz}, \mathrm{CDCl}_{3}\right) \boldsymbol{\delta}_{\mathrm{C}} 170.2(\mathrm{C}=\mathrm{O}), 169.7$ $(\mathrm{C}=\mathrm{O}), 168.6(\mathrm{C}=\mathrm{O}), 162.8(\mathrm{C}=\mathrm{O}), 92.14\left(\mathrm{C}_{1}\right), 69.7\left(\mathrm{C}_{2}\right), 69.6\left(\mathrm{C}_{5}\right), 68.3\left(\mathrm{C}_{3}\right), 67.2\left(\mathrm{C}_{4}\right), 54.7$ $\left(\mathrm{C}(\mathrm{O})_{2} \mathrm{CH}_{3}\right), 20.9\left(\mathrm{C}(\mathrm{O}) \mathrm{CH}_{3}\right), 20.7 \quad\left(\mathrm{C}(\mathrm{O}) \mathrm{CH}_{3}\right), 20.6 \quad\left(\mathrm{C}(\mathrm{O}) \mathrm{CH}_{3}\right) ; \quad \mathrm{HRMS} \quad\left[\mathrm{M}+\mathrm{NH}_{4}\right]^{+}$ calculated $\mathrm{C}_{13} \mathrm{H}_{22} \mathrm{O}_{10} \mathrm{~N}$ : 352.1283; found: 352.1246 .

\subsection{Methyl 2,3,4-tri-O-acetyl- $\alpha$-D-mannopyranosyluronate dibenzyl 1-phosphate (6)}

From 5: To a stirred solution of $5(550 \mathrm{mg}, 1.65 \mathrm{mmol}, 1.0$ equiv.) and oven dried anhydrous $\mathrm{K}_{2} \mathrm{CO}_{3}$ (360 mg, $2.64 \mathrm{mmol}, 1.6$ equiv.) in anhydrous dichloromethane $(5.5 \mathrm{~mL}$ ) was added trichloroacetonitrile $(0.37 \mathrm{~mL}, 4.62 \mathrm{mmol}, 2.8$ equiv. $)$. The solution was stirred at room temperature for $24 \mathrm{~h}$, whereupon TLC analysis (hexane/ethyl acetate, 1/1) indicated conversion of the starting material to a higher $\mathrm{R}_{\mathrm{f}}$ spot. The dark brown solution was filtered through Celite ${ }^{\circledR}$, washing with dichloromethane and concentrated in vacuo to afford methyl $(2,3,4$, -tri- $O$-acetyl- $\beta$-D-mannopyranose $)$ uronate trichloroacetimidate as a pale brown oil 
(774 mg, $1.62 \mathrm{mmol}, 88 \%$ ). This crude material (774 mg, $1.62 \mathrm{mmol}, 1.0$ equiv.) was dissolved in anhydrous dichloromethane $(15 \mathrm{~mL})$, powdered $4 \AA$ molecular sieves were added and the suspension stirred for $2 \mathrm{~h}$. Dibenzyl phosphate $(770 \mathrm{mg}, 2.75 \mathrm{mmol}, 1.7$ equiv.) was then added and stirring continued for $30 \mathrm{~min}$. The solution was then cooled to -10 ${ }^{\circ} \mathrm{C}$ and TMSOTf $(0.15 \mathrm{~mL}, 810 \mu \mathrm{mol}, 0.5$ equiv. $)$ added dropwise. The solution was warmed slowly to room temperature over $1 \mathrm{~h}$. TLC analysis (hexane/ethyl acetate, 1/1) indicated complete conversion of starting material to a lower $\mathrm{R}_{\mathrm{f}}$ spot. The light orange reaction mixture was quenched by addition of $\mathrm{Et}_{3} \mathrm{~N}$ (until $\mathrm{pH}=7$ ) and filtered over Celite ${ }^{\mathrm{TM}}$ washing with dichloromethane $(20 \mathrm{~mL})$. The organic layer was then washed with saturated aqueous $\mathrm{NaHCO}_{3}$ solution $(25 \mathrm{~mL})$, distilled water $(25 \mathrm{~mL})$, brine $(25 \mathrm{~mL})$, dried $\left(\mathrm{MgSO}_{4}\right)$, concentrated in vacuo to give a yellow oil. This crude material was purified by silica gel column chromatography eluting with toluene/acetone $(10 / 1,7 / 1,3 / 1)$ to afford $\mathbf{6}$ as a colourless oil (223 mg, $0.38 \mathrm{mmol}, 34 \%)$. $\mathrm{R}_{\mathrm{f}} 0.30$ (hexane/ethyl acetate, 1/1); ${ }^{1} \mathrm{H}$ NMR (400 $\left.\mathrm{MHz}, \mathrm{CDCl}_{3}\right) \boldsymbol{\delta}_{\mathrm{H}}$ 7.35-7.34 (8H, m, ArH), 7.19-7.17 (2H, m, ArH), $5.70(1 \mathrm{H}, \mathrm{dd}, J=6.4,1.9$ $\left.\mathrm{Hz}, \mathrm{H}_{1}\right), 5.41-5.31\left(2 \mathrm{H}, \mathrm{m}, \mathrm{H}_{3}, \mathrm{H}_{4}\right), 5.24\left(1 \mathrm{H}, \mathrm{d}, J=2.1 \mathrm{~Hz}, \mathrm{H}_{2}\right), 5.09\left(4 \mathrm{H}, \mathrm{m}, \mathrm{CH}_{2} \mathrm{Ph}\right), 4.39$ $\left(1 \mathrm{H}, \mathrm{d}, J=8.8 \mathrm{~Hz}, \mathrm{H}_{5}\right), 3.69\left(3 \mathrm{H}, \mathrm{s}, \mathrm{C}(\mathrm{O}) \mathrm{OCH}_{3}\right), 2.13\left(3 \mathrm{H}, \mathrm{s}, \mathrm{C}(\mathrm{O}) \mathrm{CH}_{3}\right), 2.05(3 \mathrm{H}, \mathrm{s}$, $\left.\mathrm{C}(\mathrm{O}) \mathrm{CH}_{3}\right), 2.01\left(3 \mathrm{H}, \mathrm{s}, \mathrm{C}(\mathrm{O}) \mathrm{CH}_{3}\right) ;{ }^{13} \mathrm{C} \mathrm{NMR}\left(100 \mathrm{MHz}, \mathrm{CDCl}_{3}\right) \boldsymbol{\delta}_{\mathrm{C}} 169.6(\mathrm{C}=\mathrm{O}), 169.5$ $(\mathrm{C}=\mathrm{O}), 169.5(\mathrm{C}=\mathrm{O}), 167.2(\mathrm{C}=\mathrm{O}), 129.1(\mathrm{Ar}-\mathrm{C}), 128.7(\mathrm{Ar}-\mathrm{C}), 128.7(\mathrm{Ar}-\mathrm{C}), 128.2(\mathrm{Ar}-\mathrm{C})$, $128.1(\mathrm{Ar}-\mathrm{C}), 94.7\left(\mathrm{C}_{1}\right), 70.8\left(\mathrm{C}_{5}\right), 70.1\left(\mathrm{CH}_{2} \mathrm{Ph}\right), 69.9\left(\mathrm{CH}_{2} \mathrm{Ph}\right), 68.2\left(\mathrm{C}_{2}\right), 67.6\left(\mathrm{C}_{3}\right), 66.4$ $\left(\mathrm{C}_{4}\right), 52.8\left(\mathrm{C}(\mathrm{O})_{2} \mathrm{CH}_{3}\right), 21.5\left(\mathrm{C}(\mathrm{O}) \mathrm{CH}_{3}\right), 20.7\left(\mathrm{C}(\mathrm{O}) \mathrm{CH}_{3}\right), 20.6\left(\mathrm{C}(\mathrm{O}) \mathrm{CH}_{3}\right) ;{ }^{31} \mathrm{P}$ NMR $(161$ $\left.\mathrm{MHz}, \mathrm{CDCl}_{3}\right) \boldsymbol{\delta}_{\mathrm{P}}-3.20(1 \mathrm{P}, \mathrm{s})$; HRMS $[\mathrm{M}+\mathrm{H}]^{+}$calculated for $\mathrm{C}_{27} \mathrm{H}_{32} \mathrm{O}_{13} \mathrm{P}: 595.5158$; found: 595.1586. These data were in good agreement with literature values. ${ }^{5}$

From 4: Uronate 4 (180 mg, $0.4 \mathrm{mmol}, 1.0$ equiv.) and powdered $4 \AA$ molecular sieves were dissolved in anhydrous dichloromethane $(5 \mathrm{~mL})$ and stirred under a $\mathrm{N}_{2}$ atmosphere at RT for $12 \mathrm{~h}$. Dibenzyl phosphate (198 mg, $0.7 \mathrm{mmol}, 1.7$ equiv.) was added and stirred for $30 \mathrm{~min}$. $\mathrm{N}$-iodosuccinimide $(0.14 \mathrm{~g}, 0.6 \mathrm{mmol}, 1.5$ equiv.) and silver trifluoromethanesulfonate (33 $\mathrm{mg}, 0.1 \mathrm{mmol}, 0.3$ equiv.) were added at $-30{ }^{\circ} \mathrm{C}$ and the temperature was raised to $-10{ }^{\circ} \mathrm{C}$ over $40 \mathrm{~min}$. TLC analysis (hexane/ethyl acetate, 1/1) indicated complete conversion of the starting material to a higher $\mathrm{R}_{\mathrm{f}}$ spot. The dark red reaction mixture was quenched through the addition of triethylamine until $\mathrm{pH}=7$, filtered through Celite ${ }^{\mathrm{TM}}$ and diluted with dichloromethane $(25 \mathrm{~mL})$. The organic layer was washed with saturated aqueous $\mathrm{Na}_{2} \mathrm{~S}_{2} \mathrm{O}_{3}$ solution $(15 \mathrm{~mL})$, saturated aqueous sodium hydrogen carbonate solution $(15 \mathrm{~mL})$, distilled water $(15 \mathrm{~mL})$ and brine $(15 \mathrm{~mL})$. The organic layer was dried $\left(\mathrm{MgSO}_{4}\right)$, filtered and concentrated under reduced pressure to afford a dark orange oil. Purification by silica gel column chromatography, eluting with hexane/ethyl acetate $(3 / 1,2 / 1,1 / 1)$, afforded 6 as a colourless oil (61 mg, $100 \mu \mathrm{mol}, 23 \%)$.

\subsection{Methyl 2,3,4-tri-O-acetyl- $\alpha$-D-mannopyranosyluronate 1-phosphate (bis- triethylammonium salt) (7)}

A suspension of 6 (200 mg, $0.34 \mathrm{mmol}, 1.0$ equiv.) and 10\% Pd/C (15 mg, $0.14 \mathrm{mmol}, 0.2$ eq. per $\mathrm{Bn})$ in anhydrous methanol $(5 \mathrm{~mL})$ was stirred under an atmosphere of hydrogen (1 atm, balloon) at room temperature for $5 \mathrm{~h}$. TLC analysis (hexane/ethyl acetate, 1/2) showed complete conversion of starting material to a lower $\mathrm{R}_{\mathrm{f}}$ spot. The reaction mixture was filtered through Celite ${ }^{\circledR}$, washing with methanol and the filtrate treated with $\mathrm{Et}_{3} \mathrm{~N}(95 \mu \mathrm{L}, 0.68 \mathrm{mmol}$, 2.0 equiv.) followed by solvent removal in vacuo to afford methyl 7 as a white solid (148 $\mathrm{mg}$, $0.24 \mathrm{mmol}, 71 \%)$. $\mathrm{R}_{\mathrm{f}} 0.45$ (ethyl acetate/methanol/water, 5/3/1); $[\alpha]_{D}^{26}=+16.05 \quad(c=0.3$, $\mathrm{MeOH}) ;{ }^{1} \mathrm{H}$ NMR $\left(400 \mathrm{MHz}, \mathrm{CDCl}_{3}\right) \boldsymbol{\delta}_{\mathrm{H}} 5.62\left(1 \mathrm{H}, \mathrm{d}, J=7.0 \mathrm{~Hz}, \mathrm{H}_{1}\right), 5.47(1 \mathrm{H}, \mathrm{dd}, J=9.9$, $\left.3.3 \mathrm{~Hz}, \mathrm{H}_{3}\right), 5.37-5.30\left(2 \mathrm{H}, \mathrm{m}, \mathrm{H}_{2}, \mathrm{H}_{4}\right), 4.70\left(1 \mathrm{H}, \mathrm{d}, J=10.0 \mathrm{~Hz}, \mathrm{H}_{5}\right), 3.70\left(3 \mathrm{H}, \mathrm{s}, \mathrm{CO}_{2} \mathrm{CH}_{3}\right)$, $2.93\left(12 \mathrm{H}, \mathrm{q}, J=6.6 \mathrm{~Hz},\left[\mathrm{CH}_{3} \mathrm{CH}_{2}\right]_{3} \mathrm{NH}^{+}\right), 2.13\left(3 \mathrm{H}, \mathrm{s}, \mathrm{C}(\mathrm{O}) \mathrm{CH}_{3}\right), 2.03\left(3 \mathrm{H}, \mathrm{s}, \mathrm{C}(\mathrm{O}) \mathrm{CH}_{3}\right)$, $1.96\left(3 \mathrm{H}, \mathrm{s}, \mathrm{C}(\mathrm{O}) \mathrm{CH}_{3}\right), 1.25\left(18 \mathrm{H}, \mathrm{t}, J=6.9 \mathrm{~Hz},\left[\mathrm{CH}_{3} \mathrm{CH}_{2}\right]_{3} \mathrm{NH}^{+}\right) ;{ }^{13} \mathrm{C} \mathrm{NMR}(100 \mathrm{MHz}$, 
$\left.\mathrm{CDCl}_{3}\right) \boldsymbol{\delta}_{\mathrm{C}} 169.9(2 \times \mathrm{C}=\mathrm{O}), 169.6(\mathrm{C}=\mathrm{O}), 168.6(\mathrm{C}=\mathrm{O}), 93.6\left(\mathrm{C}_{1}\right), 69.6\left(\mathrm{C}_{2}\right), 69.5\left(\mathrm{C}_{5}\right), 68.6$ $\left(\mathrm{C}_{3}\right), 67.1\left(\mathrm{C}_{4}\right), 52.5\left(\mathrm{CO}_{2} \mathrm{CH}_{3}\right), 45.6\left(\mathrm{~N}\left(\mathrm{CH}_{2} \mathrm{CH}_{3}\right)_{3}\right), 20.9\left(\mathrm{C}(\mathrm{O}) C_{3}\right), 20.7\left(\mathrm{C}(\mathrm{O}) \mathrm{CH}_{3}\right), 20.6$ $\left(\mathrm{C}(\mathrm{O}) \mathrm{CH}_{3}\right), 9.2\left(\mathrm{~N}\left(\mathrm{CH}_{2} \mathrm{CH}_{3}\right)_{3}\right) ;{ }^{31} \mathrm{P} \mathrm{NMR}\left(160 \mathrm{MHz}, \mathrm{CDCl}_{3}\right) \boldsymbol{\delta}_{\mathrm{P}}-0.90(1 \mathrm{P}, \mathrm{s}) ; \mathrm{HRMS}[\mathrm{M}+\mathrm{H}]^{+}$ calculated for $\mathrm{C}_{13} \mathrm{H}_{19} \mathrm{O}_{13} \mathrm{P}: 413.0951$; found: 413.0945 .

\section{7. $\alpha$-D-mannopyranuronic acid 1-phosphate (disodium salt) $(8)$}

From 7: To a stirred solution of 7 (130 mg, $0.21 \mathrm{mmol}, 1.0$ equiv.) in methanol/water (3 $\mathrm{mL} / 1.5 \mathrm{~mL})$ was added triethylamine $(3 \mathrm{~mL})$. The solution was stirred for $18 \mathrm{~h}$ at room temperature, whereupon TLC analysis (acetonitrile/water with 4 drops of $\mathrm{NH}_{4} \mathrm{OH}, 2 / 1$ ) indicated conversion of starting material to a lower $\mathrm{R}_{\mathrm{f}}$ spot. The solution was concentrated in vacuo (water bath temperature not exceeding $30{ }^{\circ} \mathrm{C}$ ) to afford a yellow residue. This was passed down an ion-exchange column (Dowex ${ }^{\circledR} 50 \mathrm{~W}-\mathrm{X} 4 \mathrm{Na}^{+}$form, 200-400 mesh) eluting with water. The sugar containing fractions were pooled and freeze dried to afford $\mathbf{8}$ as a fluffy cream solid (53 mg, $0.19 \mathrm{mmol}, 96 \%$ ). $\mathrm{R}_{\mathrm{f}} 0.33$ (acetonitrile/water with 4 drops $\mathrm{NH}_{4} \mathrm{OH}, 2 / 1$ ); $[\alpha]_{D}^{26}=+22.22\left(c=0.45, \mathrm{H}_{2} \mathrm{O}\right) ;{ }^{1} \mathrm{H}$ NMR $\left(400 \mathrm{MHz}, \mathrm{D}_{2} \mathrm{O}\right) \boldsymbol{\delta}_{\mathbf{H}} 5.28\left(1 \mathrm{H}, \mathrm{d}, J_{\mathrm{H}-\mathrm{P}}=8.6 \mathrm{~Hz}, \mathrm{H}_{1}\right)$, $4.02\left(1 \mathrm{H}, \mathrm{d}, J=10.0 \mathrm{~Hz}, \mathrm{H}_{4}\right), 3.89-3.83\left(2 \mathrm{H}, \mathrm{m}, \mathrm{H}_{2}, \mathrm{H}_{3}\right), 3.75-3.65\left(1 \mathrm{H}, \mathrm{m}, \mathrm{H}_{5}\right) ;{ }^{13} \mathrm{C} \mathrm{NMR}$ $\left(100 \mathrm{MHz}, \mathrm{D}_{2} \mathrm{O}\right) \boldsymbol{\delta}_{\mathrm{c}} 177.4(\mathrm{C}=\mathrm{O}), 95.2\left(\mathrm{C}_{1}\right), 72.9\left(\mathrm{C}_{4}\right), 71.0\left(\mathrm{C}_{2}\right), 70.0\left(\mathrm{C}_{3}\right), 69.0\left(\mathrm{C}_{5}\right) ;{ }^{31} \mathrm{P}$ NMR (161 MHz, $\left.\mathrm{D}_{2} \mathrm{O}\right) \boldsymbol{\delta} \mathbf{P} 1.35(1 \mathrm{P}, \mathrm{s})$; HRMS [M-H] ${ }^{-}$calculated for $\mathrm{C}_{6} \mathrm{H}_{11} \mathrm{O}_{10} \mathrm{P}: 273.0012$; found: 273.0013.

From 9: D-mannose (5.00 g, $30.0 \mathrm{mmol}, 1.0$ equiv.) and DMAP (61 mg, $0.5 \mathrm{mmol}, 0.02$ equiv.) were dissolved in anhydrous pyridine $(70 \mathrm{~mL})$ and cooled to $0{ }^{\circ} \mathrm{C}$. Acetic anhydride (18.0 mL, $190 \mathrm{mmol}, 6.8$ equiv.) was added dropwise and reaction warmed to room temperature and stirred for 71 hours. After this time the solution was poured onto iced water $(100 \mathrm{~mL})$ and stirred vigorously for $1 \mathrm{~h}$, whereupon the majority of the solvent was removed in vacuo and the water extracted with ethyl acetate $(2 \times 50 \mathrm{~mL})$. The combined organic extracts were washed with water $(50 \mathrm{~mL})$, saturated aqueous $\mathrm{NaHCO}_{3}$ solution $(3 \times 50 \mathrm{~mL})$, brine $(2 \times 50 \mathrm{~mL})$, dried $\left(\mathrm{MgSO}_{4}\right)$, and concentrated in vacuo to give a yellow oil. This crude material was purified by silica gel column chromatography eluting with EtOAc/hexane (2/1) to afford (1,2,3,4,6)-O-acetyl-D-mannose as a colourless syrup (9.80 g, $25.1 \mathrm{mmol}, 90 \%)$. This material (9.80 g, $25.1 \mathrm{mmol}, 1.0$ equiv.) and phosphoric acid (14.1 g, $144.0 \mathrm{mmol}, 5.7$ equiv.) were dissolved in anhydrous THF $(20 \mathrm{~mL})$ and the solvent removed in vacuo. The resulting syrup was stirred at room temperature under high vacuum for 1 hour $(0.35 \mathrm{kPa})$. The temperature was ramped to $60{ }^{\circ} \mathrm{C}$ over a period of 30 minutes and stirred for a further $2 \mathrm{~h}$ under vacuum $(0.35 \mathrm{kPa})$. The reaction was cooled to room temperature, THF $(20 \mathrm{~mL})$ was added and the solution further cooled to $0{ }^{\circ} \mathrm{C}$. The reaction was then quenched using $25 \%$ $\mathrm{NH}_{4} \mathrm{OH}$ solution $(12 \mathrm{~mL})$, the resulting precipitate filtered off and washed with ice-cold THF (10 mL). To the filtrate was added $\mathrm{LiOH}\left(3.08 \mathrm{~g}, 128 \mathrm{mmol}, 5.1\right.$ equiv.) in $\mathrm{H}_{2} \mathrm{O}(5 \mathrm{~mL})$ and the solution stirred at room temperature overnight. The reaction was then neutralised using IR120- $\mathrm{H}^{+}$ion exchange resin and filtered through a Whatman ${ }^{\circledR}$ GF/A glass microfibre filter. The solvent was evaporated in vacuo and the residue treated with $\mathrm{MeOH}(30 \mathrm{~mL})$. The resulting suspension was centrifuged at $4000 \mathrm{rpm}$ for $5 \mathrm{mins}$, the supernatant removed, the pellets washed with ice cold $\mathrm{MeOH}$ and then dried in vacuo to give $\alpha$-D-mannose-1phosphate (3.74 g, $14.5 \mathrm{mmol}, 56 \%)$ as a white amorphous solid. ${ }^{1} \mathrm{H}$ NMR (400 $\mathrm{MHz}$, $\left.\mathrm{CDCl}_{3}\right) \boldsymbol{\delta}_{\mathrm{H}} 5.23\left(1 \mathrm{H}, \mathrm{d}, J=8.6 \mathrm{~Hz}, \mathrm{H}_{1}\right), 3.82-3.87\left(2 \mathrm{H}, \mathrm{m}, \mathrm{H}_{2}, \mathrm{H}_{3}\right), 3.75-3.82\left(2 \mathrm{H}, \mathrm{m}, \mathrm{H}_{5}\right.$, $\left.\mathrm{H}_{6 \mathrm{~b}}\right), 3.63\left(1 \mathrm{H}, \mathrm{dd}, J=11.7,6.1 \mathrm{~Hz}, \mathrm{H}_{6 \mathrm{a}}\right), 3.50\left(1 \mathrm{H}\right.$, apt, $\left.J=9.7 \mathrm{~Hz}, \mathrm{H}_{4}\right) ;{ }^{13} \mathrm{C} \mathrm{NMR}(100$ $\left.\mathrm{MHz}, \mathrm{CDCl}_{3}\right) \boldsymbol{\delta}_{\mathrm{C}} 94.1\left(\mathrm{~d}, J_{1, \mathrm{P}}=4.4 \mathrm{~Hz}, \mathrm{C}_{1}\right), 72.0\left(\mathrm{C}_{5}\right), 70.2\left(\mathrm{~d}, J_{2, \mathrm{P}}=7.3 \mathrm{~Hz}, \mathrm{C}_{2}\right), 69.3\left(\mathrm{C}_{3}\right)$, $66.2\left(\mathrm{C}_{4}\right), 60.4\left(\mathrm{C}_{6}\right) ;{ }^{31} \mathrm{P}$ NMR $\left(161 \mathrm{MHz}, \mathrm{D}_{2} \mathrm{O}\right) \boldsymbol{\delta} \mathbf{P} 1.79\left(\mathrm{~d}, J_{\mathrm{P}, 1}=7.8 \mathrm{~Hz}\right) ; \mathrm{HRMS}[\mathrm{M}+\mathrm{Li}]^{+}$ calculated for $\mathrm{C}_{6} \mathrm{H}_{13} \mathrm{O}_{9} \mathrm{PLi}: 267.0457$; found: 267.0469. 


\section{Oxidation:}

\section{Secondary Oxidant $\mathrm{NaOCl}$.}

$\alpha$-D-mannose-1-phosphate ( $89 \mathrm{mg}, 0.33 \mathrm{mmol}, 1.0$ equiv.) and TEMPO (9 mg, $0.06 \mathrm{mmol}$, 0.2 equiv.) were dissolved in a mixture of $\mathrm{H}_{2} \mathrm{O}$ and $\mathrm{MeCN}(2 \mathrm{~mL}, 1: 1, v / v)$ at $0{ }^{\circ} \mathrm{C}$. To this solution, aqueous $1 \mathrm{M} \mathrm{NaOH}$ was added to $\mathrm{pH} 9 . \mathrm{NaOCl}$ solution $(1 \mathrm{~mL}$, available chlorine $10 \%$ ) was then added slowly to the rapidly stirring solution. The $\mathrm{pH}$ was maintained at 9 by adding $1 \mathrm{M} \mathrm{NaOH}$ several times over the course of the reaction. After 2 hours, the reaction mixture was concentrated and $\mathrm{MeOH}(5 \mathrm{~mL})$ was added to the resultant residue causing a precipitate to form. This suspension was centrifuged at $4000 \mathrm{rpm}$ for 5 minutes, the supernatant removed, the pellet washed (once with $\mathrm{MeOH}$ and twice with $\mathrm{MeCN}$ ) and dried in vacuo to give $\mathbf{8}$ (23 $\mathrm{mg}, 0.08 \mathrm{mmol}, 21 \%)$ as a white amorphous solid.

\section{Secondary Oxidant BAIB}

$\alpha$-D-mannose-1-phosphate (505 mg, $1.85 \mathrm{mmol}, 1.0$ equiv.), TEMPO (46 mg, $0.3 \mathrm{mmol}, 0.15$ equiv.) and bis(acetoxy)iodobenzene (1.29 g, $3.99 \mathrm{mmol}, 2.2$ equiv.) were dissolved in a mixture of $\mathrm{H}_{2} \mathrm{O} / \mathrm{MeCN}(8 \mathrm{~mL}, 1: 1, v / v)$. The reaction was then stirred at room temperature for 24 hours, concentrated in vacuo and $\mathrm{MeOH}(10 \mathrm{~mL})$ added to the resultant residue, causing a precipitate to form. This suspension was centrifuged at $4000 \mathrm{rpm}$ for 5 minutes, the supernatant removed, the pellet washed (once with $\mathrm{MeOH}$ and once with $\mathrm{MeCN}$ ) and dried in vacuo to give crude 8. This material was dissolved in $\mathrm{H}_{2} \mathrm{O}$ and passed through a Sephadex ${ }^{\circledR}$ G-25 gel filtration column. The sugar containing fractions were pooled, treated with an $\mathrm{NH}_{4}{ }^{+}$ ion exchange resin, filtered and freeze-dried to yield $8(182 \mathrm{mg}, 0.67 \mathrm{mmol}, 30 \%)$ as needlelike crystals. See above procedure for analytical data for $\mathbf{8}$.

\subsection{Guanosine-5'-phosphoromorpholidate}

Method A (Khorana $\left.{ }^{20}\right)$ : Dowex ${ }^{\circledR} 50 \mathrm{~W}-\mathrm{X} 8$ resin $\left(\mathrm{H}^{+}\right.$form, $17 \times 700 \mathrm{~mm}$ column) was exchanged to its morpholine form by passing a $10 \%$ aqueous morpholine solution through the column $(200 \mathrm{~mL})$. Exchange was indicated through a basic $\mathrm{pH}$ of the eluate $(\mathrm{pH} 10.87)$. Guanosine 5'-monophosphate disodium salt ( $\mathrm{Na}_{2} \mathrm{GMP}$ ) (407 mg, $1.0 \mathrm{mmol}, 1.0$ equiv.) in distilled water $(50 \mathrm{~mL})$ was then applied to the column and eluates containing sodium morpholine-GMP were concentrated to a final volume of $10 \mathrm{~mL}$. Morpholine $(210 \mu \mathrm{L}, 2.4$ mmol, 2.4 equiv.) and $t$-butanol $(10 \mathrm{~mL})$ were added and the solution was heated to $100{ }^{\circ} \mathrm{C}$ at reflux, whilst a solution of dicyclohexylcarbodiimide $(825 \mathrm{mg}, 4.0 \mathrm{mmol}, 4.0$ equiv.) in $t$ butanol $(15 \mathrm{~mL})$ was added dropwise over $2 \mathrm{~h}$. The solution was heated at reflux for a further $3 \mathrm{~h}$, where TLC analysis (isopropyl alcohol/ $\mathrm{NH}_{4} \mathrm{OH} /$ water, $\left.7 / 1 / 2\right)$ showed two new spots $\left(\mathrm{R}_{\mathrm{f}}\right.$ $=0.52+0.93)$. The yellow solution cooled to room temperature and was left for $72 \mathrm{~h}$ whereupon a white crystalline by-product (dicyclohexylurea) had formed. The suspension was filtered, concentrated in vасио and the remaining aqueous phase extracted with diethyl ether $(2 \times 20 \mathrm{~mL})$. The combined aqueous phases were concentrated in vacuo then purified by Sephadex ${ }^{\circledR}$ G-25 column chromatography, eluting with a linear gradient of triethylammonium bicarbonate $(0.005-0.5 \mathrm{M})$. Fractions containing the product were collected and concentrated under reduced pressure. Residual bicarbonate was removed by sequential evaporations from methanol $(2 \times 25 \mathrm{~mL})$. The residue was dissolved in methanol (10 mL), 4-morpholine- $N, N^{\prime}$-dicyclohexylcarboxamidine (600 mg, $2.0 \mathrm{mmol}, 2.0$ equiv.) was added then the solution concentrated under reduced pressure. The residue was dissolved in methanol $(5 \mathrm{~mL})$ and diethyl ether $(25 \mathrm{~mL})$ was added to form a white precipitate. The liquid was decanted and the precipitate was washed with diethyl ether $(2 \times 10 \mathrm{~mL})$, redissolved in water and lyophilized to afford the title compound as a cream solid (198 mg, $0.27 \mathrm{mmol}, 27 \%$ ). $\mathrm{R}_{\mathrm{f}} 0.52$ (isopropyl alcohol/ammonium hydroxide/water, $\left.7 / 1 / 2\right) ;{ }^{31} \mathrm{P}\left\{{ }^{1} \mathrm{H}\right\}$ $\left(161 \mathrm{MHz}, \mathrm{D}_{2} \mathrm{O}\right) \boldsymbol{\delta} \mathbf{P}-7.41(1 \mathrm{P}, \mathrm{s})$. 
Method B (Mukaiyama $\left.{ }^{21}\right)$ : Dowex ${ }^{\circledR} 50 \mathrm{~W}-\mathrm{X} 8$ resin $\left(\mathrm{H}^{+}\right.$form, $17 \times 700 \mathrm{~mm}$ column) was exchanged to its morpholine form by passing a $10 \%$ aqueous morpholine solution through the column $(200 \mathrm{~mL})$. Exchange was indicated through a basic $\mathrm{pH}$ of the eluate $(\mathrm{pH} 10.87)$. Guanosine 5'-monophosphate disodium salt ( $\mathrm{Na}_{2} \mathrm{GMP}$ ) (500 mg, $1.23 \mathrm{mmol}, 1.0$ equiv.) in distilled water $(50 \mathrm{~mL})$ was applied to the column and eluates containing sodium morpholineGMP were concentrated in vacuo to afford a cream solid. To a solution of morpholine-GMP in dimethyl sulfoxide (DMSO) $(10 \mathrm{~mL})$ was added morpholine $(0.58 \mathrm{~mL}, 6.64 \mathrm{mmol}, 5.4$ equiv.) to form an opaque white solution. After stirring for $5 \mathrm{~min}$ at room temperature, dipyridyl disulfide (0.89 g, $4.06 \mathrm{mmol}, 3.3$ equiv.) was added slowly to the solution followed by triphenyl phosphine (1.06 g, $4.06 \mathrm{mmol}, 3.3$ equiv.). The resultant bright yellow solution was stirred for $4 \mathrm{~h}$ at room temperature and a solution of sodium iodide $(0.1 \mathrm{M}$ in acetone) was then added until a precipitate formed. The This was collected by filtration, dissolved in distilled water and purified by Sephade ${ }^{\circledR}$ G-25 column chromatography, eluting with a linear gradient of triethylammonium bicarbonate (TEAB) $(0.005-0.5 \mathrm{M})$. Fractions containing the product were collected and concentrated under reduced pressure. Residual TEAB was removed by sequential evaporations from methanol $(2 \times 25 \mathrm{~mL})$ and the solid was lyophilized to afford the title compound as a white solid (161 mg, $0.37 \mathrm{mmol}, 30 \%)$. $\mathrm{R}_{\mathrm{f}} 0.52$ (isopropyl alcohol/ $\mathrm{NH}_{4} \mathrm{OH} /$ water, 7/1/2); $[\alpha]_{D}^{26}=-16.0\left(c=0.5, \mathrm{H}_{2} \mathrm{O}\right) ;{ }^{1} \mathrm{H}$ NMR $(400 \mathrm{MHz}$, $\left.\mathrm{D}_{2} \mathrm{O}\right) \delta_{\mathbf{H}} 7.93\left(1 \mathrm{H}, \mathrm{s}, \mathrm{H}_{8}\right), 5.79\left(1 \mathrm{H}, \mathrm{d}, J=5.0 \mathrm{~Hz}, \mathrm{H}_{1^{\prime}}\right), 4.67\left(1 \mathrm{H}, \mathrm{t}, J=5.1 \mathrm{~Hz}, \mathrm{H}_{2}{ }^{\prime}\right),, 4.41$ $\left(1 \mathrm{H}, \mathrm{t}, J=4.8 \mathrm{~Hz}, \mathrm{H}_{3}{ }^{\prime}\right), 4.20\left(1 \mathrm{H}, \mathrm{bs}, \mathrm{H}_{4}{ }^{\prime}\right), 3.95-3.88\left(2 \mathrm{H}, \mathrm{m}, \mathrm{H}_{5}, \mathrm{H}_{5}{ }^{\prime}\right), 3.47(4 \mathrm{H}, \mathrm{t}, J=4.5$ $\mathrm{Hz}, 2 \times \mathrm{CH}_{2}$ morpholine), 2.85-2.82 (4H, m, $2 \times \mathrm{CH}_{2}$ morpholine); ${ }^{13} \mathrm{C}$ NMR $(101 \mathrm{MHz}$, $\mathrm{D}_{2} \mathrm{O}$ ) $\boldsymbol{\delta}_{\mathbf{c}} 159.5$ (guanine C), 154.5 (guanine C), 151.68 (guanine $\mathrm{C}$ ), $137.25\left(\mathrm{C}_{8}\right), 116.4$ (guanine $\mathrm{C}), 87.3\left(\mathrm{C}_{1^{\prime}}\right), 83.7\left(\mathrm{C}_{4}{ }^{\prime}\right), 83.7\left(\mathrm{C}_{1}{ }^{\prime}\right), 73.7\left(\mathrm{C}_{2}\right), 70.4\left(\mathrm{C}_{3}{ }^{\prime}\right), 66.9\left(\mathrm{CH}_{2}\right.$ morpholine),

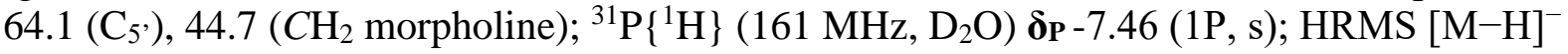
calculated for $\mathrm{C}_{4} \mathrm{H}_{20} \mathrm{~N}_{6} \mathrm{O}_{8} \mathrm{P}: 431.1080$; found: 431.1082 .

\subsection{General procedure for sugar nucleotide synthesis:}

Glycosyl 1-phosphate and GMP-morpholidate were exchanged to their bis-triethylammonium salt forms prior to the reaction and lyophilised. Glycosyl 1-phosphate (bis-triethylammonium salt, 1.0 equiv.), GMP-morpholidate (bis-triethylammonium salt, 1.5 equiv.) and activator were each co-evaporated with toluene or pyridine $(3 \times 2 \mathrm{~mL})$ and then dissolved in DMF or pyridine, respectively. The reaction mixture was stirred at room temperature and conversion monitored by TLC analysis (isopropyl alcohol/ $\mathrm{NH}_{4} \mathrm{OH} /$ water, 6/3/1). The reaction mixture was concentrated under reduced pressure (water bath temperature not exceeding $30{ }^{\circ} \mathrm{C}$ ) and dried under high vacuum before analysis by crude ${ }^{1} \mathrm{H}$ and ${ }^{31} \mathrm{P}$ NMR to confirm presence of a NDP-sugar.

\subsection{General procedure for sugar nucleotide deprotection:}

The crude reaction mixture was suspended in a mixture of $\mathrm{MeOH}$ and $\mathrm{H}_{2} \mathrm{O}$ (1:1) then $\mathrm{Et}_{3} \mathrm{~N}$ was added until $\mathrm{pH}=9$. The reaction mixture was stirred for $24 \mathrm{~h}$ at room temperature or until TLC analysis (isopropyl alcohol/ $/ \mathrm{NH}_{4} \mathrm{OH} /$ water, 6/3/1) indicated conversion of starting material to a lower $R_{f}$ value spot. The reaction mixture was concentrated under reduced pressure (water bath temperature not exceeding $30{ }^{\circ} \mathrm{C}$ ) to give a dark yellow residue. The resultant residue was dissolved in $\mathrm{H}_{2} \mathrm{O}$ and in entries using DCI, passed down a Thermoscientific X30 SPE column (HyperSep C18, $6 \mathrm{~mL}$ ), eluting with $\mathrm{H}_{2} \mathrm{O}$ to remove DCI. The resulting aliquots were purified by strong-anion exchange chromatography.

Table 1, Entry 5: 7 (22 mg, $53 \mu \mathrm{mol}, 1.0$ equiv.), GMP-morpholidate (36 mg, $84 \mu \mathrm{mol}, 1.5$ equiv.) and DCI (6 mg, $53 \mu \mathrm{mol}, 1.0$ equiv.) were dissolved in pyridine ( $1 \mathrm{~mL})$ and stirred for 
$120 \mathrm{~h}$. Following deprotection/purification as described in $4.9 \& 4.10$ this afforded 1 as a white powder (15 mg, $24 \mu \mathrm{mol}, 46 \%)$.

Table 1, Entry 4: 7 (44 mg, $0.10 \mathrm{mmol}, 1.0$ equiv.) and GMP-morpholidate (73 mg, 0.17 mmol, 1.6 equiv.) were dissolved in pyridine $(1.5 \mathrm{~mL})$ and stirred for $48 \mathrm{~h}$. DCI $(11 \mathrm{mg}, 93$ $\mu$ mol, 1.0 equiv.) was added and the reaction mixture was stirred for a further $96 \mathrm{~h}$. Following deprotection/purification as described in $4.9 \& 4.10$ this afforded 1 as a white powder (14 mg, $22 \mu \mathrm{mol}, 22 \%$ ).

\subsection{Guanosine 5'-( $\alpha$-D-mannopyranuronic diphosphate) (1)}

$\mathrm{R}_{\mathrm{f}} 0.19$ (isopropyl alcohol/ $\mathrm{NH}_{4} \mathrm{OH} /$ water, 6/3/1); ${ }^{1} \mathbf{H} \mathbf{N M R}\left(600 \mathrm{MHz} ; \mathrm{D}_{2} \mathrm{O}\right) \delta 7.96(1 \mathrm{H}, \mathrm{s}$, $\left.\mathrm{H}_{8^{\prime}}{ }^{\prime}\right), 5.79\left(1 \mathrm{H}, \mathrm{d}, J=6.1 \mathrm{~Hz}, \mathrm{H}_{1}{ }^{\prime}\right), 5.39\left(1 \mathrm{H}, \mathrm{dd}, J=8.0,1.7 \mathrm{~Hz}, \mathrm{H}_{1}\right), 4.64(1 \mathrm{H}$, hidden, $\left.\mathrm{H}_{2}{ }^{\prime}\right), 4.35\left(1 \mathrm{H}, \mathrm{dd}, J=4.8,3.3 \mathrm{~Hz}, \mathrm{H}_{3^{\prime}}\right), 4.34-4.29\left(1 \mathrm{H}, \mathrm{m}, \mathrm{H}_{4}{ }^{\prime}\right), 4.18(2 \mathrm{H}, \mathrm{dd}, J=5.2,3.5$ $\left.\mathrm{Hz}, \mathrm{H}_{5}{ }^{\prime}\right), 3.95\left(1 \mathrm{H}, \mathrm{d}, J=10.0 \mathrm{~Hz}, \mathrm{H}_{5}\right), 3.88\left(1 \mathrm{H}, \mathrm{dd}, J=2.2,3.3 \mathrm{~Hz}, \mathrm{H}_{2}\right), 3.78(1 \mathrm{H}, \mathrm{dd}, J=$ 9.6, 3.3 Hz, H $\left.\mathrm{H}_{3}\right), 3.64\left(1 \mathrm{H}, \mathrm{t}, J=9.7 \mathrm{~Hz}, \mathrm{H}_{4}\right)$; $\delta_{\mathrm{P}}\left(101 \mathrm{MHz} \mathrm{D}_{2} \mathrm{O}\right) \delta-11.2,-13.7$; HRMS [M$\mathrm{H}]^{-}$calculated for $\mathrm{C}_{16} \mathrm{H}_{22} \mathrm{~N}_{5} \mathrm{O}_{17} \mathrm{P}_{2}$ : 618.0491; found: 618.0484.

\subsection{Guanosine 5'-( $\alpha$-D-mannopyranuronic diphosphate) (1)}

GDP- $\alpha$-D-mannose $(1.6 \mathrm{mg}, 2.5 \mu \mathrm{mol})$ and $\mathrm{NAD}^{+}(3.5 \mathrm{mg}, 5.25 \mu \mathrm{mol})$ were dissolved in buffer $(0.9 \mathrm{ml}, 200 \mathrm{mM}$ sodium phosphate, $\mathrm{pH} 7.4,1 \mathrm{mM}$ DTT, $0.5 \mathrm{mM} \mathrm{MgCl} 2)$ and GMD $(0.8 \mathrm{mg} / \mathrm{ml}$ final concentration) was added to give total volume $1 \mathrm{ml}$. The mixture was incubated at room temperature with gentle shaking whilst being monitored by SAX on a Poros HQ 50 column. Samples $(10 \mu \mathrm{l})$ were taken at time points, mixed with methanol (10 $\mu \mathrm{l})$, vortexed and centrifuged to remove precipitated protein. The supernatant (10 $\mu \mathrm{l})$ was analysed by SAX. After 21 hours the conversion of GDP- $\alpha$-D-mannose into 1 reached $70 \%$. The enzymatic transformation was stopped by addition of methanol $(1 \mathrm{ml})$. The mixture was vortexed for 1 minute and centrifuged. The supernatant was filtered through a syringe disc filter $(0.45 \mu \mathrm{m}$, PTFE) and the resulting crude product was purified by SAX. Fractions containing 1 were pooled and freeze dried to give the title compound as a bisammonium salt $(1.2 \mathrm{mg}, 2.0 \mu \mathrm{mol}, 70 \%)$. See analytical data above for $\mathbf{1}$.

\section{Acknowledgements}

Keele University are thanked for a PhD studentship to L.B. Work at the John Innes Centre is supported by the UK BBSRC Institute Strategic Program on Molecules from Nature - Products and Pathways [BBS/E/J/000PR9790] and the John Innes Foundation; and the InnovateUK IBCatalyst [BB/M02903411 and EP/N033167/10].We also thank the EPSRC UK National Mass Spectrometry Facility (NMSF) at Swansea University.

\section{References}

1. $\quad$ Li, Z.; Kosorok, M. R.; Farrell, P. M.; Laxova, A.; West, S. E.; Green, C. G.; Collins, J.; Rock, M. J.; Splaingard, M. L. JAMA, 2005, 293, 581-88.

2. a) Lee, K. Y.; Mooney, D. J. Prog. Polym. Sci., 2012, 37, 106-26 b) Sabra, W.; Zeng, A. P.; Deckwer, W. D. Appl. Microbiol. Biotechnol., 2001, 56, 315-25 c) Ertesvåg, H. Front. Microbiol., 2015, 6, 523 d) Jia, J.; Richards, D. J.; Pollard, S.; Tan, Y.; Rodriguez, J.; Visconti, R. P.; Trusk, T. C.; Yost, M. J.; Yao, H.; Markwald, R. R.; Mei, Y. Acta Biomater., 2014, 10, 4323-31.

3. Snook, C.F.; Tipton, P.A.; Beamer, L.J. Biochemistry, 2003, 42, 4658-68. 
4. Ahmadipour, S.; Pergolizzi, G.; Rejzek, M.; Field, R. A.; Miller, G. J. Org. Lett., 2019, 21, 4415-19.

5. Zhang, Q.; Howell, P. L.; Overkleeft, H. S.; Filippov, D. V.; van der Marel, G. A.; Codée, J. D. C. Carbohydr. Res., 2017, 450, 12-18.

6. Wagner, G. K.; Pesnot, T.; Field, R. A. Nat. Prod. Rep., 2009, 26, 1172-94.

7. Muthana, M. M.; Qu, J.; Xue, M.; Klyuchnik, T.; Siu, A.; Li, Y.; Zhang, L.; Yu, H.; Li, L.; Wang, P. G.; Chen, X. Chem. Commun., 2015, 51, 4595-98.

8. Rejzek, M.; Kannathasan, V. S.; Wing, C.; Preston, A.; Westman, E. L.; Lam, J. S.; Naismith, J. H.; Maskell, D. J.; Field, R. A. Org. Biomol. Chem., 2009, 7, 1203-10.

9. Weïwer, M.; Sherwood, T.; Green, D. E.; Chen, M.; DeAngelis, P. L.; Liu, J.; Linhardt, R. J. J. Org. Chem., 2008, 73, 7631-37.

10. Roseman, S.; Distler, J. J.; Moffatt, J. G.; Khorana, H. G. J. Am. Chem. Soc., 1961, 83, 659-63.

11. Beswick, L.; Miller, G. J., Molbank, 2017, 2017, M947.

12. MacDonald, D. L. J. Org. Chem., 1962, 27, 1107-09.

13. Wadouachi, A.; Kovensky, J. Molecules, 2011, 16, 3933-68.

14. Watt, G. M.; Flitsch, S. L.; Fey, S.; Elling, L.; Kragl, U. Tetrahedron: Asymmetry, 2000, 11, 621-28.

15. Davis, N. J.; Flitsch, S. L. Tetrahedron Lett., 1993, 34, 1181-84.

16. Timmons, S. C.; Jakeman, D. L. Org. Lett., 2007, 9, 1227-30.

17. a) Ahmadipour, S.; Miller, G. J. Carbohydr. Res., 2017, 451, 95-109 b) Ahmadipour, S.; Beswick, L.; Miller, G. J. Carbohydr. Res., 2018, 469, 38-47.

18. Tsukamoto, H.; Kahne, D. Bioorg. Med. Chem. Lett., 2011, 21, 5050-53.

19. Wagstaff, B.; Rejzek, M.; Kuhaudomlarp, S.; Hill, L.; Mascia, I.; Nepogodiev, S.; Field, R. A. J. Biol. Chem., 2019, 294, 9172-85.

20. Moffatt, J.; Khorana, H. J. Am. Chem. Soc., 1961, 83, 649-58.

21. Mukaiyama, T.; Hashimoto, M. Tetrahedr. Lett., 1971, 44, 2284. 